\title{
Collaborative protection of marine environment in the Guangdong-Hong Kong-Macao Greater Bay Area
}

\author{
Xie Wei ${ }^{1, *}$ \\ ${ }^{1}$ Law School, Guangdong Finance \& Economic University, 21 Luntou Road, Haizhu District, Guangzhou 510320, China
}

\begin{abstract}
The quality of Marine ecological environment is one of the necessary conditions for building a world-class bay area. The ecological environment in the coastal waters of Guangdong-Hong Kong-Macao Greater Bay Area is seriously polluted, it is urgently needed for three places to strengthen coordinated Marine ecological and environmental management. Under the guidance of outline development plan for the Greater Bay Area and with the goal of building a Marine ecological civilization in the Greater Bay Area, the coordination mechanism of administrative management and the standard system for Marine ecological environmental protection should be improved, land and sea overall planning should be used for Marine ecological environment protection.
\end{abstract}

\section{Status}

With the rapid development of Marine economy, the Marine environment in Guangdong-Hong Kong-Macao Greater Bay Area is facing severe pollution, poor water quality and marine floating garbage. Taking the Pearl River Estuary as an example, from 2003 to 2014, the Pearl River Estuary had been the most concentrated and largest sea area of "extremely poor water quality" which was worse than the fourth type of water quality in Guangdong for 12 consecutive years.[1] Both the Ecological Environmental Status Bulletin of Guangdong Province and the Marine Environmental Status Bulletin of China from 2014 to 2019 showed that the water quality of Pearl River Estuary remained worse than the fourth type of water quality.

Table 1. Water quality in Pearl River Estuary.[2]

\begin{tabular}{|c|c|c|c|c|c|c|}
\hline Index & $\mathrm{PH}$ & $\begin{array}{c}\mathrm{COD}_{\mathrm{Mn}} \\
(\mathrm{mg} / \mathrm{L})\end{array}$ & $\begin{array}{c}\mathrm{DIN} \\
(\mathrm{mg} / \mathrm{L})\end{array}$ & $\begin{array}{c}\text { DIP } \\
(\mathrm{mg} / \\
\mathrm{L})\end{array}$ & $\mathrm{TN}$ & $\mathrm{TP}$ \\
\hline Value & 7.29 & 3.01 & 2.12 & 0.11 & 3.17 & 0.26 \\
\hline
\end{tabular}

In view of the fact that the water quality of Pearl River Estuary is extremely poor, Guangdong and Hong Kong has set up 'Guangdong and Hong Kong Liaison Group on Environmental Protection' for strengthening area water quality management, established several joint action plans, jointly tackled transboundary water pollution from 1990. In 2000, it was upgraded to the Hong Kong and Guangdong Cooperation Group on Sustainable Development and Environmental Protection to further enhance cooperation on cross-boundary environmental issues. In 2016, under this framework, they established 'Marine Environment Management Task Group' and 'Cross-Border Maritime Drift-Garbage
Incident Reporting Mechanism'. However, prior to the formulation of Guangdong-Hong Kong-Macao Greater Bay Area strategy, such cooperation was mainly voluntary and initiative bilateral cooperation, with the main purpose of strengthening communication and exchanges on Marine environmental protection issues.

\section{PROBLEMS}

\subsection{Differentiated management mechanism}

The first is the key sea area control system and the universal marine environment control. Guangdong implements the General Marine Environmental Protection Planning and the Marine Environmental Protection Planning in Key Sea Areas. That is to say, the Provincial Marine Administrative Department should, in accordance with the Marine Function Zoning, the National Marine Environmental Protection Plan and the Regional Marine Environmental Protection Plan of Key Sea Areas, formulate the Provincial Marine Environmental Protection Plan of Key Sea Areas. There is no such distinction in Hong Kong. Instead, Hong Kong Waters are generally divided into ten water quality control zones and four supplementary zones. Each control zone applies specific water quality target restrictions in accordance with the actual situation of the region and implements water quality management in accordance with the water quality target requirements of the region. The establishment of key sea areas can meet the current plight of the mainland Marine environment supervision and administration departments with scarce supervision resource and insufficient administrative power. However, it also exposes the blank of supervision over the non-key sea areas. 
The second is the significant difference in Marine environmental information disclosure system. Every year, Hong Kong releases a report on the water quality of about 1,700 square kilometres of Hong Kong waters, and makes the public to know the achievement of key water quality targets in each region. Although Guangdong also releases a bulletin on Marine Environment State every year, the information on Marine environment is relatively simple and not detailed to specific sea areas. For example, every year, Hong Kong publishes the Annual Marine Water Quality Report, which reports on the state of Marine water quality in ten water control zones in Hong Kong. The Hong Kong Environment Protection Department has also set up a Dedicated Marine Water Quality Website to publish various types of Marine water quality information. There are 76 Marine monitoring stations in Hong Kong. Each month, the Environment Protection Department monitors the seawater quality of 76 water sampling stations, collects and surveys phytoplankton samples from 25 stations. The water quality of 17 typhoon shelters, yacht clubs and marinas in Hong Kong is monitored every other month. The sediment samples are collected and analysed twice a year at 60 seabed sediment sampling stations, covering all Hong Kong Waters. On the other hand, 'Guangdong Province Ocean Status Bulletin in 2017'released the water quality status of Pearl River Delta coastal waters. The water quality that meets the quality standards for class I and II seawaters is mainly distributed in the waters of Daya Bay, Dapeng Bay and Chuanshan Islands. The water quality inferior to the class IV seawater quality standards is mainly distributed in the Pearl River Estuary.

The Third is the difference of pollution accident reporting system. The law of Hong Kong requires ships to report immediately and in as much detail as possible to the Director of Marine any accident involving the actual or probable discharge of dangerous solid bulk goods from the ship, if the ship is outside the Hong Kong Waters, the captain should report the accident to the nearest coastal state. The report must be based on the guidelines and general principles adopted in relevant International Maritime Organization resolutions. Moreover, in order to enhance the effectiveness of the report, Hong Kong also requires that if the report issued by the ship is incomplete or not available, the owner must make or complete the aforementioned reports as far as practicable. It can be seen that such a report system is highly operational and has clear operational basis. In comparison, Guangdong proclaims in principle when the ship has accident or may cause marine pollution accident, the parties should report to the maritime sector or the fishery administration departments, but there is no clear stipulation on the method and content of the report, and also there is not suitable penalties for failure to perform reporting obligations, so such report system is short of operability and enforceability.

\subsection{Different marine environmental standard system}

The first is the difference of seawater quality index. The seawater quality standard applicable to Guangdong is the Seawater Quality Standard of People's Republic of China (GB 3097-1997), while Hong Kong has set different water quality indexes for the ten water control zones. There are two main differences in the water quality indicators between Guangdong and Hong Kong. In terms of rigor degree of the indicators, Hong Kong's seawater quality indicator is more stringent than Guangdong's. In terms of dissolved oxygen index, for example, Guangdong's water quality standards is respectively set up four categories of indicators, including the value of $6,5,4$, and 3 , in accordance with the sea water quality standard of class I, II, III and IV. Hong Kong applicable water quality standard, on the other hand, is divided into four types: seabed dissolved oxygen, water depth average dissolved oxygen, remaining water column dissolved oxygen, and all depths of dissolved oxygen, with the value of 2 and 4 respectively. Even within a water quality control zone, there are different water quality indicators for different sea areas. In addition, the types of indicators are set differently. For example, Hong Kong has chlorophyll and salinity indicators, while Guangdong does not have the two types of indicators.

Table 2. Sea water quality standard of Guangdong.[3]

\begin{tabular}{|c|c|c|c|}
\hline $\begin{array}{c}\text { Types } \\
\text { Index }\end{array}$ & Class II & Class III & Class IV \\
\hline TSP & $\leqq 10$ & $\leqq 100$ & $\leqq 150$ \\
\hline $\mathrm{PH}$ & $7.8 \sim 8.5$ & $6.8 \sim 8.8$ & $6.8 \sim 8.8$ \\
\hline $\mathrm{COD}$ & $\leqq 3$ & $\leqq 4$ & $\leqq 5$ \\
\hline $\mathrm{BOD}_{5}$ & $\leqq 3$ & $\leqq 4$ & $\leqq 5$ \\
\hline $\mathrm{C}_{\mathrm{d}}$ & $\leqq 0.005$ & $\leqq 0.01$ & $\leqq 0.01$ \\
\hline $\mathrm{Hg}$ & $\leqq 0.0002$ & $\leqq 0.0002$ & $\leqq 0.0005$ \\
\hline $\begin{array}{c}\mathrm{E.coli}(/ 100 \\
\mathrm{ml})\end{array}$ & $\leqq 1000$ & $\leqq 1000$ & --- \\
\hline
\end{tabular}

Table 3. Sea water quality standard of Hong Kong.[4]

\begin{tabular}{|l|l|l|l|}
\hline \multicolumn{1}{|c|}{$\begin{array}{l}\text { Flowrate } \\
\text { Index }\end{array}$} & $\begin{array}{l}>10 \text { and } \\
\leqq 200\end{array}$ & $\begin{array}{l}>200 \text { and } \\
\leqq 400\end{array}$ & $\begin{array}{l}>400 \text { and } \\
\leqq 600\end{array}$ \\
\hline TSP & 30 & 30 & 30 \\
\hline PH & $6-9$ & $6-9$ & $6-9$ \\
\hline COD & 80 & 80 & 80 \\
\hline BOD & 20 & 20 & 20 \\
\hline$C_{d}$ & 0.001 & 0.001 & 0.001 \\
\hline Hg & 0.001 & 0.001 & 0.001 \\
\hline E.coli $(/ 100 \mathrm{ml})$ & 1000 & 1000 & 1000 \\
& & & \\
\hline
\end{tabular}


The second is the difference of standard partition setting. Guangdong has classified the first, second, third and fourth categories of marine water quality standards. Although the Marine Function Zoning System has been implemented at the beginning, it is not in-depth enough, leading to the cross-functional area transfer of Guangdong marine environment pollution, so Guangdong has not yet set specific pollution discharge standards in strict accordance with detailed Marine Function Zoning. Hong Kong, on the other hand, has adopted different effluent standards for each water control area and refined them to different effluent limits for different functional areas within the same water control area.

The third is the difference in marine environment monitoring methods. The standards methods of the American Society for Material and Testing, the British Standards Institution and the American Public Health Association are generally adopted in Hong Kong. Guangdong adopts the Chinese national standard methods, including the Technical Regulations for the Evaluation of Seawater Quality, the Technical Regulations for the Environmental Monitoring and Evaluation of Seawater Bathing Beach, the Quality of Marine Sediments, and the Quality of Marine Life. For example, chlorophyll-A and sediment in Hong Kong's seawater quality indicators should refer to the US national coastal zone status assessment index and rating method.[5] Hong Kong's marine environmental standards can focus on regional characteristics, and pay attention to the fact that the standard critical value can be adjusted with the change of time and space, so they have strong flexibility and applicability. Although Guangdong has the unified standard for seawater environment, it lacks due attention and reference to regional characteristics, scientific research achievements. The Outline Law on Macao Sea Area Administration only stipulates in principle that the standards for Marine environmental quality management in Macao should be formulated in accordance with the national standards for marine environmental quality and in conformity with the conditions of Macao, but have not been published so far.

\section{Improve Collaborative Protection}

\subsection{Improve coordination management mechanism}

The common and shared marine environment determines the inevitability of regional cooperation in Marine environmental governance. Guangdong, Hong Kong and Macao have established an inter-governmental agreement cooperation model, for instance, the Environment Bureau of Hong Kong had a cooperation agreement with the Maritime Safety Administration of the Ministry of Transport on air pollution control from ships.[6] Guangdong and Macao also have cooperation experience in the protection of Hengqin Coastal wetland.[7] Now it is necessary that the coordination management should be improved since the Greater Bay Area has been set up, which means that the improvement should be aimed to the specific objects of pollution prevention and control, and the corresponding specific cooperation mechanisms, which are based on the strengthening of "one country, two systems". In other words, pollution prevention and control cooperation should be carried out under the authority coordination of central government with respect to a certain prominent problem of marine environmental pollution, and the cooperation scope should be extended to the Greater Bay Area of Guangdong, Hong Kong and Macao instead of just bilateral cooperation. For instance, the prevention and control of sea drift-garbage can be led and coordinated by the Ministry of Ecology and Environment, and a leading group for sea drift-garbage prevention and control can be set up. Its members can be composed of the leaders of " $9+2$ " city authorities in the Greater Bay Area, and the existing cooperation mechanism for Marine environmental protection between Guangdong and Hong Kong, Guangdong and Macao should be integrated into a tripartite participation mechanism.

\subsection{Coordinate environmental standards}

There are still great conflicts in the setting of specific standards for marine environmental protection among the three places, especially in Guangdong and Hong Kong. The coordination of marine environmental standards is the basis of promoting integrated marine environmental protection in the Greater Bay Area. As the Greater Bay Area shares the adjacent sea areas, it is necessary to comprehensively and systematically review the existing marine environmental standard system of the three regions under the leadership coordination mechanism of marine environmental protection. The institutional advantages of "one country, two systems" should be made full use of. Guangdong should learn from Hong Kong's advanced marine environmental standards setting, marine environmental monitoring methods, and marine environmental monitoring networks point location setting. In view of the low level of marine environmental standards, incomplete index setting, and lagging marine environmental monitoring methods, Guangdong should improve the standards level and methods of marine environmental monitoring. Macao should promptly establish and prefect the marine environmental standard system in its own sea area. Under the premise that the three parties have reached consents through consultation, the unified standards for marine environmental protection in the Greater Bay Area may be considered to facilitate exchange and sharing of marine environmental monitoring information.

\subsection{Land and sea overall planning}

The overall planning of land and sea is the fundamental way to prevent and control marine ecological environment pollution. With the continuous progress of ecological civilization construction in the Greater Bay Area, Guangdong, Hong Kong and Macao should increase frequency and intensity of joint law enforcement on marine environmental protection. Joint 
administrative law enforcement may be conducted on the issues of common maritime drift-garbage disposal, pollution prevention and control from ships, marine ecological protection zones and other aspects, so as to explore and summarize the experience and rules of joint administrative law enforcement of marine environmental protection among three parties. Under the coordination mechanism of marine environmental protection in the Greater Bay Area, the three parties should determine the procedures and means of integrated marine environmental administrative management through consultation, giving consideration to the values of environmental justice, administrative efficiency and procedural justice. Guangdong should learn from Hong Kong's procedural regulations on marine environmental administrative management, enhance the procedural and normative nature of environmental administrative management and attract the public to participate in marine environmental administrative management. Hong Kong should learn from Guangdong's practice of improving the efficiency of environmental administrative management and strengthen the enforcement of environmental administrative actions. Macao should further give full play to the advantages of executive administration mode, ensure the legitimacy of environmental administrative regulations and orders, so as to prevent and avoid unnecessary environmental administrative disputes.

\section{Conclusion}

The Development Plan Outline of the Greater Bay Area clearly requires that the marine resources and environment protection should be strengthened, the determination of land by sea should be attached greater importance to, the establishment of a total amount control system for pollutants entering the sea and a realtime online monitoring system for the marine environment should be speeded up. At the same time, it also calls for "strengthening cooperation in ecological and environmental protection between Guangdong, Hong Kong and Macao, to jointly improve the ecological environmental system." Therefore, the construction of marine ecological civilization in the Greater Bay Area has become a challenging task to be solved urgently. Guangdong, Hong Kong and Macao should improve the coordination mechanism of marine environmental protection in the Greater Bay Area under the guidance of the Development Plan Outline, coordinate with each other to determine the marine environmental standards system for the Greater Bay Area, carry out the overall planning of the land and sea areas to coordinate the administrative management of marine ecological and environmental protection.

\section{Acknowledgments}

The research for this paper forms part of a project entitled 'Research on Conflict and Coordination of Environmental Administrative Law Enforcement in the Guangdong-Hong Kong- Macao Greater Bay Area' funded by the Ministry of Education for Research in Humanities and Social Sciences in 2018 (No. 18YJA820025), and 'Research on Environmental Impact Assessment System in the Guangdong-Hong KongMacao Greater Bay Area' funded by the Guangdong Provincial Planning Project of Philosophy and Social Science in 2018 (No. GD18CFX01).

\section{References}

1. Yi Ming, NF Daily, October 20, A05,(2015).

2. Dang Ersha,etc., Journal of Dalian Ocean University,vol.34, pp 581-582, (2019).

3. Sea water quality standard (GB 3097-1997), http://www.mee.gov.cn/ywgz/fgbz/bz/bzwb/shjbh/s hjzlbz/199807/W020061027511546974673.pdf, visit on 2 October 2020.

4. Technical memorandum: effluent standards discharged into drainage and sewerage systems, inland and coastal waters, Table 10a, https://www.elegislation.gov.hk/hk/cap358AK!zhHant-HK, visit on 2 November 2020.

5. Wang Qiulu,etc.,Environment and Sustainable Development,Vol.4, pp 83-85, (2016).

6. Yi Ming, China Maritime Safety, vol. 1, pp. 74, (2017).

7. Zhuhai and Macao in Guangdong Province jointly carrying out wetland protection in Hengqin New Area,http://www.forestry.gov.cn/portal/main/s/102/c ontent-553722.html, visit on 22 June 2020. 